\title{
Is Suicide a Solution?
}

\author{
Mr. Jayant Kumar Sahu \\ MBBS IV , 2015 Batch, Gandaki Medical College, Pokhara \\ E mail: jayantsah60@gmail.com
}

Suicide is the act of intentionally causing one's own death. Suicide often stems from a deep feeling of hopelessness. The inability to see solutions to problems or to cope with challenging life circumstances may lead people to see suicide as the only option to what is really a temporary situation. Suicides are impulsive acts which occur due to stress, such as financial problems, unemployment, homelessness, poverty, mental illness, substance misuses, childhood trauma, social isolation, loss of loved ones.

According to the recent studies, numbers of male attempt suicide is approximate four times higher compared to female. According to world health organization (WHO), every year close to eight lakh people take their own life which is one person every 40 second. There are many more people who attempt suicide. Every suicide is a tragedy that affects families, communities and entire country and has long-lasting effects on the people left behind. Suicide occurs throughout the lifespan and was the second leading cause of death among 15 to 29-yearolds globally in 2016. Suicide is generally most common among those over the age of 70 years because of lack of feeling of togetherness. Ninety percent of people who commit suicide are due to mental illness, which can be completely prevented. China has one of the highest female suicide rates in the world and is only the country where it is higher than men. A suicide rate in the Nepal has ranked at $126^{\text {th }}$ by 2015 . WHO report says that 6840 suicides are committed annually in Nepal. Statistics shows that the countries with the highest suicide rates in the world are incredibly diverse. It is said that female are more likely to have thoughts of suicide. Male are more likely to use firearms to commit suicide and females use poisoning method to commit suicide.

Among these all data just as a writer, I want to ask you all "is suicide a solution for those people who think to live a life in pathetic environment? It is said in religious aspects that god has given us life to live as both happiness and sorrows are the two sides of the same coin. Life is not a fruitful cake walk many obstacles' comes and goes so try to handle it by sharing. Suicide can be prevented. If you are consulted by someone who are thinking about suicide, listen to them, recommend for psychological counselling. There is a need to increase education and awareness among medical professionals for proper counseling to the patients. 